\title{
Polyunsaturated fatty acids influence differential biosynthesis of oxylipids and other lipid mediators during bovine coliform mastitis
}

\author{
Vengai Mavangira, ${ }^{*}$ Jeffery C. Gandy, ${ }^{*}$ Chen Zhang, $†$ Valerie E. Ryman, ${ }^{*}$ A. Daniel Jones, $† \ddagger$ \\ and Lorraine M. Sordillo*1 \\ *Department of Large Animal Clinical Sciences, College of Veterinary Medicine, \\ †Department of Chemistry, and \\ ‡Department of Biochemistry and Molecular Biology, Michigan State University, East Lansing 48824
}

\begin{abstract}
Coliform mastitis is a severe and sometimes fatal disease characterized by an unregulated inflammatory response. The initiation, progression, and resolution of inflammatory responses are regulated, in part, by potent oxylipid metabolites derived from polyunsaturated fatty acids. The purpose of this study was to characterize the biosynthesis and diversity of oxylipid metabolites during acute bovine coliform mastitis. Eleven cows diagnosed with naturally occurring acute systemic coliform mastitis and 13 healthy control cows, matched for lactation number and days in milk, were selected for comparison of oxylipid and free fatty acid concentrations in both milk and plasma. Oxylipids and free fatty acids were quantified using liquid chromatography-tandem mass spectrometry. All polyunsaturated fatty acids quantified in milk were elevated during coliform mastitis with linoleic acid being the most abundant. Oxylipids synthesized through the lipoxygenase and cytochrome $\mathrm{P} 450$ pathways accounted for the majority of the oxylipid biosynthesis. This study demonstrated a complex and diverse oxylipid network, most pronounced at the level of the mammary gland. Substrate availability, biosynthetic pathways, and degree of metabolism influence the biosynthesis of oxylipids during bovine coliform mastitis. Further studies are required to identify targets for novel interventions that modulate oxylipid biosynthesis during coliform mastitis to optimize inflammation.
\end{abstract}

Key words: inflammation, mastitis, oxylipid, lipids

\section{INTRODUCTION}

Gram-negative bacteria are a predominant cause of clinical mastitis infections in dairy cows (Erskine et al., 1988; Oliveira et al., 2013). Whereas some infec-

Received March 14, 2015.

Accepted May 27, 2015.

${ }^{1}$ Corresponding author: sordillo@msu.edu tions are subclinical and self-limiting, a proportion of affected cows develop an acute and severe systemic disease resulting in significant decrease in milk production and sometimes death (Erskine et al., 1988; Hogan and Smith, 2003). Subclinical and self-limiting infections are associated with a controlled inflammatory response with a prompt return to normal tissue homeostasis and milk production (Vangroenweghe et al., 2005). Acute gram-negative mammary infections, however, are characterized by dysregulated inflammatory responses elicited by LPS (Sordillo et al., 2009). Binding of LPS to toll-like receptor 4 (TLR4) results in activation of nuclear factor $\kappa \mathrm{B}(\mathbf{N F}-\kappa \mathbf{B})$ with subsequent transcription and translation of proteins important for inflammatory mediator biosynthesis. Potent phospholipid mediators crucial for onset and progression of inflammation following LPS exposure also are released including platelet activating factor and oxidized lipids known as oxylipids (Corl et al., 2008).

The biosynthesis of oxylipids is preceded by release of their PUFA precursors, including linoleic acid (LA), arachidonic acid (ArA), eicosapentaenoic acid (EPA), and docosahexaenoic acid (DHA) from the $s n-2$ esterification site in the phospholipid glycerol backbone (Rosenthal et al., 1995). The abundance of PUFA in phospholipids is dependent on and can be modified by dietary FA composition in several species (Calder, 2008; Childs et al., 2008). Metabolism of PUFA may occur in situ on esterified forms in phospholipids or, more commonly, following their release and availability as FFA in the cytosol (Kuhn et al., 2015). The release of PUFA as free or pre-oxygenated fatty acids from the $s n-2$ ester linkage is mediated by phospholipase enzymes (Murakami et al., 2011). Several classes of phospholipase enzymes are known, but the cytosolic $\mathrm{PLA}_{2}\left(\mathbf{c} \mathbf{P L A} \mathbf{A}_{2}\right)$ is the predominant isoform class responsible for sn-2 ester linkage hydrolysis (Buczynski et al., 2009). The activation of $\mathrm{cPLA}_{2}$ is mediated by an increase in intracellular calcium in response to several stimuli, including LPS from gram-negative bacteria (Rosenthal et al., 1995). Activation of other classes of 
lipases releases other bioactive lipid mediators from cell membrane phospholipids, including endocannabinoids (Zubrzycki et al., 2014a).

Regardless of PUFA type, oxygenation can occur through enzymatic pathways such as cyclooxygenase (COX), lipoxygenase (LOX), or cytochrome P450 (CYP) and nonenzymatic auto-oxidation mediated by some reactive metabolites (Buczynski et al., 2009). The COX enzymes are bifunctional, initially abstracting a hydrogen atom mediated by a tyrosine radical at the oxygenase site and followed by addition of dioxygen to generate prostaglandin (PG) $\mathrm{G}_{2}$ (Wu et al., 2011). Then, $\mathrm{PGG}_{2}$ is reduced at the peroxidase site of $\mathrm{COX}$ into the more stable $\mathrm{PGH}_{2}$, which undergoes further metabolism by various prostaglandin synthases to a variety of bioactive prostanoids. Lipoxygenases utilize their non-heme $\mathrm{Fe}^{2+}$ to form ferrous hydroxide, which subsequently abstracts a hydrogen atom followed by insertion of molecular oxygen, forming a peroxy radical that is further converted to peroxy fatty acids (Kuhn et al., 2015). Similarly, cytochrome enzymes use their nonheme $\mathrm{Fe}^{2+}$ in mediating the oxidation, peroxidation, and hydroxylation of PUFA and some of the COX-derived prostaglandins including $\mathrm{PGE}_{2}$ and $\mathrm{PGD}_{2}$ (Spector et al., 2004).

The nonenzymatic oxidation of PUFA is primarily orchestrated by pro-oxidant metabolites such as reactive oxygen species (ROS) that include superoxide and hydrogen peroxide. Although physiologically important at low levels, ROS concentrations exceeding the cellular antioxidant capacity can induce oxidative stress where there is peroxidation of cell membrane PUFA (Sordillo et al., 2009). In dairy cows, the transition period is associated with oxidative stress related to increased ROS production by enhanced mitochondrial metabolism (Bernabucci et al., 2005). The induction of the oxidative burst mechanism used by leukocytes in killing bacteria is another major source of ROS during infections such as mastitis (Sordillo et al., 2009). The highly reactive unpaired electrons of ROS free radicals target the double bonds in PUFA and generate oxylipids, including hydroperoxy fatty acids and isoprostanes. Such auto-oxidation of PUFA differs from the enzymaticderived pathways, by producing an assortment of both positional and enantiomeric isomeric products because of lack of specificity as exhibited by enzymes (Milne et al., 2011).

The initial oxygenation FA products from either enzymatic or nonenzymatic oxidation are subjected to further downstream metabolism to form a diverse network of oxylipids. Prostaglandin $\mathrm{H}_{2}$ metabolites are converted to downstream prostaglandins by specific prostaglandin synthases. For example, specific prostaglandin synthases metabolize $\mathrm{PGH}_{2}$ to prostaglandins
$\mathrm{D}_{2}, \mathrm{E}_{2}, \mathrm{~F}_{2 \alpha}$, and $\mathrm{I}_{2}$. The LOX-derived peroxy $\mathrm{FA}$ are further converted into leukotrienes, lipoxins, resolvins, and protectins (Kuhn et al., 2015), whereas CYP-derived fatty acid epoxides are further converted to fatty acid diols by soluble epoxide hydrolases. At least 140 oxylipids have been characterized to date, most with potent regulatory effects on inflammation (Tam, 2013).

Oxylipid biosynthesis is complex and is regulated by available PUFA substrates, activation of oxygenation pathways, and the extent to which initial oxygenation products are metabolized. A broader understanding of oxylipid diversity, changes in patterns of oxylipid accumulation, and their direct effects on inflammatory responses during bovine mastitis is required to enable evaluation of efficacious intervention modalities that promote resolution of inflammation. The purpose of this study, therefore, was to investigate the biosynthesis of oxylipid metabolites during acute naturally occurring coliform mastitis infection in dairy cows. Based on previous studies documenting increased FFA during mastitis (Atroshi et al., 1989a,b), the hypothesis for this study was that oxylipid biosynthesis would be correlated with their FFA substrates in both milk and plasma during naturally occurring bovine coliform mastitis.

\section{MATERIALS AND METHODS}

\section{Chemicals}

Acetonitrile, methanol, and formic acid of liquid chromatography-mass spectrometry grade were purchased from Sigma-Aldrich (St. Louis, MO). Deuterated and nondeuterated oxylipid standards were purchased from Cayman Chemical (Ann Arbor, MI). Butylated hydroxy toluene was purchased from ACROS (Thermo Fisher, Fair Lawn, NJ), EDTA and triphenylphosphine were purchased from Sigma-Aldrich, and indomethacin was purchased from Cayman Chemical.

\section{Animals}

This study was approved by the Michigan State University Institutional Animal Care and Use Committee (IACUC) and cows were enrolled with client consent. The study was conducted at a commercial dairy operation in Michigan with about 3,300 lactating cows with an approximate rolling herd average milk production of $12,250 \mathrm{~kg}$. Cows were housed in freestall barns and grouped according to lactation number, DIM, and milk yield. Cows were milked 2 times daily. Diets were formulated to meet the energy requirements based on production (Table 1) and feed was delivered 2 times/d as TMR. 
Table 1. Nutrient composition (\% of DM unless otherwise noted) of the diet for the experimental animals ${ }^{1}$

\begin{tabular}{lc}
\hline Item & Nutrient analysis \\
\hline $\mathrm{DM}$ & 47.64 \\
Forage DM & 40.87 \\
$\mathrm{CP}$ & 17.23 \\
$\mathrm{MP}$ & 11.97 \\
$\mathrm{ME}, \mathrm{Mcal} / \mathrm{kg}$ & 2.98 \\
$\mathrm{NE}, \mathrm{Mcal} / \mathrm{kg}$ & 1.79 \\
$\mathrm{ADF}$ & 16.23 \\
$\mathrm{NDF}$ & 29.56 \\
Forage ADF & 10.92 \\
Forage NDF & 17.46 \\
NFC & 42.36 \\
Starch (nonsugar) & 29.85 \\
Fat & 4.34 \\
\hline
\end{tabular}

${ }^{1}$ Supplemented with: vitamin $\mathrm{A}, 8,369 \mathrm{IU} / \mathrm{kg}$, vitamin $\mathrm{D}, 1,455 \mathrm{IU} /$ $\mathrm{kg}$, and vitamin E, $33 \mathrm{IU} / \mathrm{kg}$; minerals (\% of DM): $1.04 \mathrm{Ca}, 0.48 \mathrm{P}$, $1.1 \mathrm{~K}, 0.34 \mathrm{Mg}, 0.26 \mathrm{~S}, 0.56 \mathrm{Na}, 0.32 \mathrm{Cl}$, 0.35 Salt; Ca:P ratio = 2.17; trace minerals $(\mathrm{mg} / \mathrm{kg}): 51.8 \mathrm{Zn}, 7.6 \mathrm{Fe}, 11.5 \mathrm{Cu}, 37.0 \mathrm{Mn}, 0.6 \mathrm{Co}$ 0.6 I, 0.37 Se; DCAD = 27.6 mEq/100 g; Rumensin $9.3 \mathrm{~g} / \mathrm{t}$ (Elanco, Indianapolis, IN).

\section{Study Design}

Twenty-four multiparous dairy cows of at least third lactation were enrolled and divided into coliform mastitis $(\mathrm{n}=11)$ and healthy control $(\mathrm{n}=13)$ groups. The coliform mastitis group cows had cultured positive for Escherichia coli in milk samples and exhibited signs of systemic clinical disease. Negative bacterial cultures on milk, absence of overt clinical signs, and an SCC of $<250,000$ cells $/ \mathrm{mL}$ on last test day were required for the healthy control group. Bacterial milk cultures were performed on blood agar and selective media for coliform bacteria according to the National Mastitis Council guidelines (Hogan et al., 1999). Briefly, individual mammary gland quarter milk $(10 \mu \mathrm{L})$ was streaked onto a sheep blood agar and selective media using a sterile loop inoculator. Cultures were incubated at $37^{\circ} \mathrm{C}$, read at 24 and $48 \mathrm{~h}$, and considered positive for coliform growth based on presence of 3 or more colonies on both blood and selective media. Clinical signs for diagnosis of acute systemic coliform mastitis included elevated rectal temperature $\left(>39.2^{\circ} \mathrm{C}\right)$, tachycardia (heart rate $>80$ beats $/ \mathrm{min}$ ), tachypnea (respiratory rate $>30$ breaths/min), episcleral injection, local signs of mammary gland inflammation including discoloration, swelling, heat, pain on palpation, and typical serum-like watery milk. Cows in the mastitis group had heavy coliform bacterial growth $(>100 \mathrm{cfu})$ on milk culture and at least 2 of the clinical signs of systemic disease. Milk and blood samples were collected at the same time from each cow within $12 \mathrm{~h}$ following a clinical diagnosis of systemic coliform mastitis and from the lactation and DIM matched healthy control cows.

\section{Lipidomics}

Targeted PUFA, MUFA, SFA, and oxylipids were quantified using liquid chromatography tandem mass spectrometry (LC-MS/MS). Plasma from whole blood collected in EDTA anticoagulant and milk samples were mixed with an antioxidant reducing agent mixture to prevent degradation of preformed oxylipids and prevent ex vivo lipid peroxidation (O'Donnell et al., 2009). The antioxidant reducing agent mixture consisted of $50 \%$ methanol, $25 \%$ ethanol, and $25 \%$ water with 0.9 $\mathrm{m} M$ butylated hydroxy toluene, $0.54 \mathrm{~m} M$ EDTA, 3.2 $\mathrm{m} M$ triphenylphosphine, and $5.6 \mathrm{~m} M$ indomethacin. Samples were flash frozen in liquid nitrogen and stored at $-80^{\circ} \mathrm{C}$ until analyses.

\section{Internal Standards}

A mixture of internal standards containing 5(S)hydroxyeicosatetraenoic- $\mathrm{d}_{8}$ acid [5(S)-HETE_d $\left.d_{8}\right]$, 15(S)-hydroxyeicosatetraenoic- $\mathrm{d}_{8}$ acid [15(S)-HETE $\left.d_{8}\right], 8(9)$-epoxyeicosatrienoic- $d_{11}$ acid [8(9)-EET_ $d_{11}$, prostaglandin E2-d $d_{9}\left(\mathrm{PGE} 2 \_d_{9}\right)$, 8,9-dihydroxyeicosatrienoic- $\mathrm{d}_{11}$ acid (8,9-DHET_d $\left.d_{11}\right)$, arachidonic acid- $\mathrm{d}_{8}$ $\left(\right.$ AA_d $\left.d_{8}\right), 2$-arachidonoyl glycerol-d $d_{8}\left(2-A_{-} d_{8}\right)$, and arachidonoyl ethanolamide- $\mathrm{d}_{8}\left(\mathrm{AEA} \_d_{8}\right)$ was prepared to final concentrations of $0.25,0.25,0.5,0.5,0.25,50$, 2 , and $0.25 \mu M$, respectively. The internal pure standards mixture was added into each sample and used to generate a 6-point standard curve ranging from 500 to $0.001 \mu M$ in concentration of unlabeled fatty acid and oxylipid standards.

\section{Sample Processing}

Frozen plasma and whole milk samples were thawed on ice and processed as follows: $4 \mathrm{~mL}$ of milk was combined with $9.15 \mathrm{~mL}$ of $4^{\circ} \mathrm{C}$ acetonitrile, and $2 \mathrm{~mL}$ of plasma was combined with $5 \mathrm{~mL}$ of $4^{\circ} \mathrm{C}$ methanol and 2 $\mu \mathrm{L}$ of $88 \%$ formic acid. To each sample mixture, $15 \mu \mathrm{L}$ of internal standard cocktail was added, and the sample was vortexed for $2 \mathrm{~min}$, incubated at room temperature for $15 \mathrm{~min}$, and centrifuged at 4,816 $\times \mathrm{g}$ for $20 \mathrm{~min}$ at $4^{\circ} \mathrm{C}$. For plasma, the supernatant was diluted with 95 $\mathrm{mL}$ of HPLC-grade water and $95 \mu \mathrm{L}$ of formic acid, and supernatant in milk samples was diluted with $170 \mathrm{~mL}$ of HPLC-grade water and $170 \mu \mathrm{L}$ of formic acid.

\section{Solid-Phase Extraction}

Solid-phase extraction was performed for each sample with Oasis HLB 12cc (500 mg) LP Extraction Columns (Waters, Milford, MA). Columns were conditioned with 
$6 \mathrm{~mL}$ of methanol followed by $6 \mathrm{~mL}$ of HPLC water. Extracts were loaded onto the columns, which were then washed with $6 \mathrm{~mL}$ of $20 \%$ methanol and dried under full vacuum for $4 \mathrm{~min}$. Analytes were eluted with $6 \mathrm{~mL}$ of methanol:acetonitrile 50:50 (vol:vol). The volatile solvents were removed under vacuum using a Savant SpeedVac (ThermoQuest, Holbrook, NY). The residues were reconstituted in $100 \mu \mathrm{L}$ of methanol and transferred to a microcentrifuge tube containing $50 \mu \mathrm{L}$ of water. The mixture was centrifuged at $14,000 \times g$ for $10 \mathrm{~min}$ at $4^{\circ} \mathrm{C}$ and then the supernatant was transferred to an auto-sampler vial with a low volume insert and stored at $-20^{\circ} \mathrm{C}$ until analyzed.

\section{LC-MS/MS Analyses}

The quantification of metabolites was accomplished on a Waters Acquity UPLC coupled to a Waters Xevo TQ-S triple quadrupole mass spectrometer (Waters) using multiple reaction monitoring. Chromatography separation was performed with an Ascentis Express C18 HPLC column, $10 \mathrm{~cm} \times 2.1 \mathrm{~mm}, 2.7 \mu \mathrm{m}$ (Supelco, Bellefonte, PA) held at $50^{\circ} \mathrm{C}$. The autosampler was held at $10^{\circ} \mathrm{C}$. Mobile phase $\mathrm{A}$ was water with $0.1 \%$ formic acid, and mobile phase B was acetonitrile. Flow rate was fixed at $0.3 \mathrm{~mL} / \mathrm{min}$. Liquid chromatography separation took $15 \mathrm{~min}$ with linear gradient steps programmed as follows (A:B ratio): time 0 to $0.5 \mathrm{~min}$ $(99: 1)$, to $(60: 40)$ at $2.0 \mathrm{~min}$; to $(20: 80)$ at $8.0 \mathrm{~min}$; to $(1: 99)$ at $9.0 \mathrm{~min} ; 0.5 \mathrm{~min}$ held at (1:99) until min 13.0; then return to $(99: 1)$ at $13.01 \mathrm{~min}$, and held at this condition until 15.0 min. All oxylipids and fatty acids were detected using electrospray ionization in negativeion mode, whereas the endocannabinoids were detected using positive-ion mode. Cone voltages and collision voltages were optimized for each analyte using Waters QuanOptimize software (see Appendix for multiple reaction monitoring parameters).

\section{Statistical Analyses}

Statistical analyses were performed using SAS software (version SAS 9.4; SAS institute Inc., Cary, NC). Data were expressed as means \pm standard errors of the mean and tested for normality. Where Gaussian distribution was satisfied, $t$-tests for independent means were performed. Data deviating from the Gaussian distribution were either square root- or log-transformed before analyses. An ANOVA and Tukey test for comparison between means were performed to determine differences among FA concentrations in the same sample type (milk or plasma). Pearson correlations were calculated for multiple relationships among FA substrates;
FA substrates and their oxylipid metabolites; related upstream and downstream oxylipid metabolites and concentrations of the same substrate/metabolite in milk versus plasma. The levels of significance for correlation analyses were adjusted for multiple comparisons. Statistical significance was set at $\alpha=5 \%$, and data are presented as means $\pm \mathrm{SEM}$.

\section{RESULTS}

Fatty acids quantified in milk and plasma included PUFA (ArA, LA, EPA, and DHA), MUFA (oleic acid), and SFA (palmitic and stearic acids). All PUFA concentrations were greater in milk during coliform mastitis; however, only the elevations in LA concentrations were reflected systemically in plasma (Figure 1). Fold differences of PUFA in milk between mastitis and healthy cows were highest for LA (5.1) followed, in decreasing order, by ArA (3.8), DHA (3.0), and EPA (2.4). Linoleic acid was the most abundant PUFA in both milk and plasma in both mastitis and healthy cows (Figure 1). Higher concentrations of oleic acid in milk during coliform mastitis were reflected systemically in plasma, whereas no differences in the SFA were detected (Figure 2).

A lipidome of 63 oxylipid species was targeted by the LC-MS/MS protocol used in this study. Thirty oxylipids were detected in milk and 27 were detected in plasma. The oxylipids leukotriene $\mathrm{B}_{4}\left(\mathbf{L T B}_{4}\right)$, 8,9-epoxyeicosatrienoic acid (8,9-EET), and 17-hydroxydocosahexaenoic acid (17-HDoHE) were detected in milk only and accounted for the differences in the number of detected oxylipids between milk and plasma. A significantly $(P<0.05)$ higher proportion of the fraction of total oxylipid changes was observed in milk oxylipids (60\%) compared with plasma oxylipids (32\%) during coliform mastitis. Oxylipids that were not detectable in $50 \%$ or more cows in the study groups were excluded from all statistical analyses and are reported together with their corresponding limits of detection (Table 2). The limit of detection was defined as the concentration at which the peak response for an analyte was 3 times that of the noise (signal:noise $=3$ ).

Oxylipids detected were representative of the known enzymatic pathways (COX, LOX, and CYP) and nonenzymatic pathways. The COX pathway was represented by prostaglandin metabolites from ArA metabolism, accounting for only 8 and $9 \%$ of the fraction of total oxylipids in milk and plasma, respectively. Concentrations of $\mathrm{PGE}_{2}$ and 6-ketoPGF $\mathrm{P}_{1 \alpha}$ were elevated significantly in milk (Table 3), but only the concentrations of 6-ketoPGF ${ }_{1 \alpha}$ (a stable metabolite of $\mathrm{PGI}_{2}$ ) were reflected systemically in plasma. 

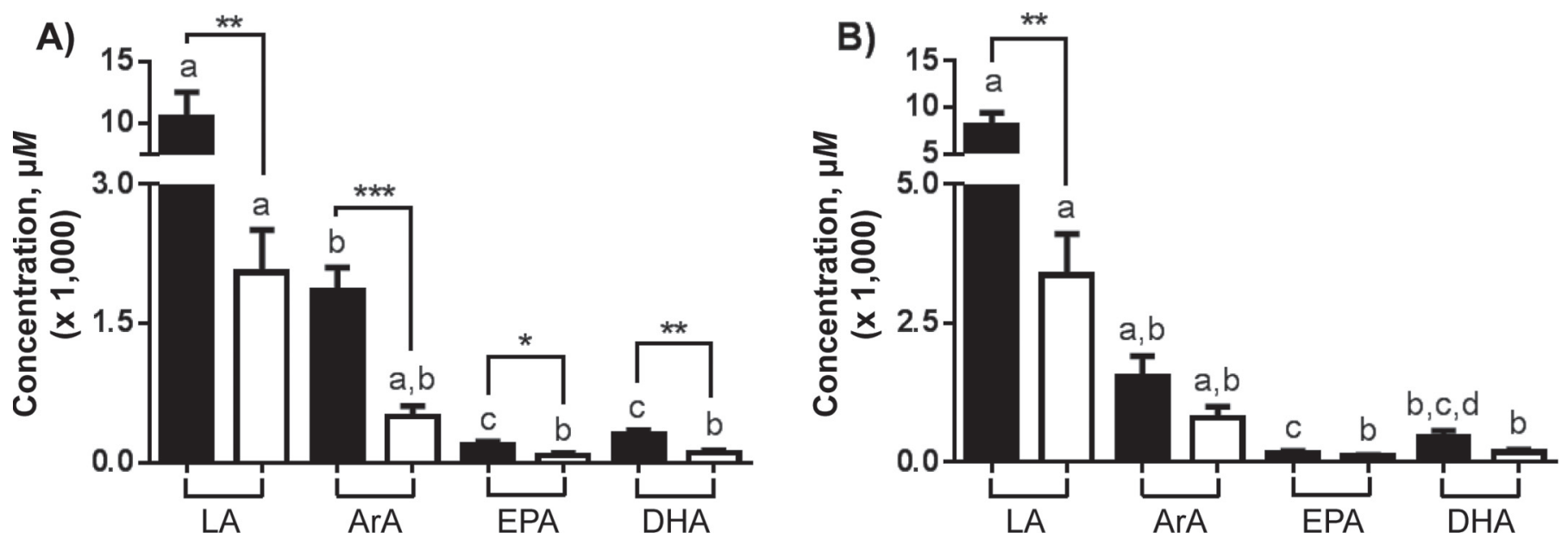

Figure 1. Concentrations (mean \pm SEM, $\mu M$ ) of PUFA differed for all PUFA in milk (A) but only for linoleic acid (LA) in plasma (B) between coliform mastitis (solid bars) and healthy control (open bars) cows. Linoleic acid was most abundant among PUFA but similar to arachidonic acid (ArA) in control milk and plasma and mastitis plasma) within an experimental group; EPA = eicosapentaenoic acid, DHA = docosahexaenoic acid. ${ }^{*} P<0.05,{ }^{* *} P<0.01,{ }^{* * *} P<0.001$; bars with different letters $(\mathrm{a}-\mathrm{d})$ differ $(P<0.05)$ among PUFA within an experimental group (mastitis or control).

Lipoxygenase-derived oxylipids (Table 4) accounted for the highest proportion of the fraction of total oxylipid metabolites detected in both milk (48\%) and plasma (45\%). The hydroxy metabolite concentrations, 9- and 13-hydroxyoctadecadienoic acids (HODE) from LA and 5- and 15-hydroxyeicosatetraenoic acids (HETE) from ArA were elevated in milk during coliform mastitis; however, their respective downstream ketone derivatives 9- and 13-oxooctadecadienoic acid (oxoODE) from LA and 5- and 15-oxoeicosatetraenoic acid (oxoETE) from ArA were not different. Lipoxygenase-derived $\mathrm{LTB}_{4}$ and lipoxin $\mathrm{A}_{4}\left(\mathbf{L X A}_{4}\right)$ similarly were elevated in milk, but $\mathrm{LXA}_{4}$ was significantly lower in plasma during mastitis. The DHA metabolite resol- vin $\mathrm{D}_{2}\left(\mathbf{R v D}_{2}\right)$ was significantly decreased in plasma during mastitis.

The CYP enzymatic metabolism of LA, ArA, and EPA generated oxylipids that accounted for 36 and $36 \%$ of the fraction of total oxylipids detected in milk and plasma, respectively (Table 5). The epoxidation metabolites of LA, epoxyoctadecenoic acids $(\mathbf{9 , 1 0}$ - and 12,13-EpOME), were significantly elevated in milk of coliform mastitis cows but the epoxide hydration products (dihydroxyoctadecenoic acids; 9,10- and 12,13-DiHOME) were significantly lower in plasma of mastitis cows. In contrast, the ArA epoxide 11,12-epoxyeicosatrienoic (EET) was elevated in plasma of control cows. The hydroxylation product of ArA, 20-HETE,
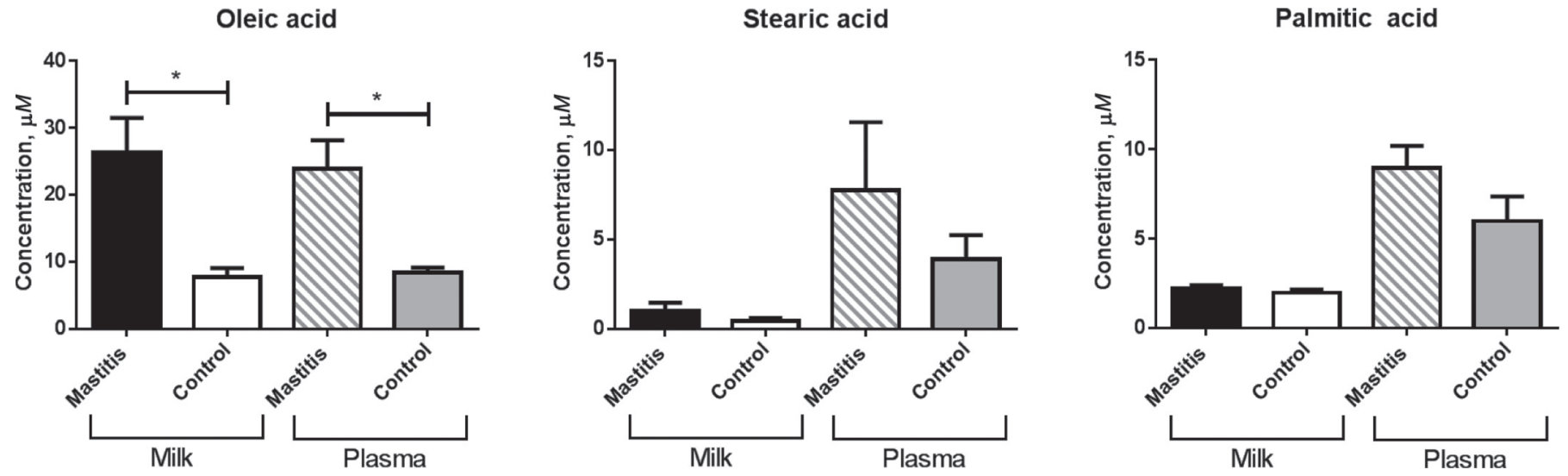

Figure 2. Milk and plasma concentrations (mean \pm SEM; $\mu M)$ of oleic acid were greater in coliform mastitis $(\mathrm{n}=11)$ than control $(\mathrm{n}=13)$ cows but no differences were detected for stearic and palmitic acids. Solid and open black bars represent milk samples; diagonally striped and gray bars represent plasma samples. ${ }^{*} P<0.05$. 
Table 2. Concentrations and limits of detection (mean $\pm \mathrm{SEM} ; \mathrm{n} M$ ) for oxylipids inconsistently detected in milk and plasma from coliform mastitis (total $\mathrm{n}=11$ ) and control (total $\mathrm{n}=13$ ) cows

\begin{tabular}{|c|c|c|c|c|c|c|c|c|}
\hline Sample & Oxylipid $^{1}$ & \multicolumn{3}{|c|}{ Mastitis group } & \multicolumn{3}{|c|}{ Control cows } & $\mathrm{LOD}^{2}$ \\
\hline \multirow{3}{*}{ Milk } & 8,9 -EET & $5 / 11(45)$ & 0.15 & 0.10 & $0 / 13(0)$ & - & - & 0.02 \\
\hline & 19,20-EpDPE & $2 / 11(18)$ & 0.87 & 0.16 & $0 / 13(0)$ & - & - & 0.60 \\
\hline & $15-\mathrm{dPGJ}_{2}$ & $2 / 11(18)$ & 0.10 & 0.02 & $0 / 13(0)$ & - & - & 0.05 \\
\hline \multirow{7}{*}{ Plasma } & 14,15-EET & $0 / 11(0)$ & - & - & $0 / 13(0)$ & - & - & 0.94 \\
\hline & 8,9 -EET & $0 / 11(0)$ & - & - & 0/13(0) & - & - & 0.02 \\
\hline & 19,20-EpDPE & $0 / 11(0)$ & - & - & $1 / 13(8)$ & 0.76 & 0.00 & 0.60 \\
\hline & 17-HDoHE & $5 / 11(45)$ & 0.30 & 0.11 & $0 / 13(0)$ & - & - & 0.11 \\
\hline & 6-ketoPGF ${ }_{1 \alpha}$ & $5 / 11(45)$ & 1.1 & 0.23 & $0 / 13(0)$ & - & - & 0.44 \\
\hline & $15-\mathrm{dPGJ}_{2}$ & 2/11 (18) & 0.07 & 0.01 & 0/13 (0) & - & - & 0.05 \\
\hline & 14,15-EpETE & $1 / 11(9)$ & 0.01 & 0.00 & $0 / 13(0)$ & - & - & 0.01 \\
\hline
\end{tabular}

${ }^{1} \mathrm{EET}=$ epoxyeicosatrienoic acid; EpDPE $=$ epoxydocosapentaenoic acid; 15 -dPGJ $\mathrm{d}_{2}=15$-deoxyprostaglandin $\mathrm{J}_{2} ; \mathrm{EpETE}=$ epoxyeicosatetraenoic acid; $\mathrm{LTB}_{4}=$ leukotriene $\mathrm{B}_{4}$; HDoHE $=$ hydroxy-docosahexaenoic acid; 6-ketoPGF ${ }_{1 \alpha}=6$-keto prostaglandin $\mathrm{F}_{1 \alpha}$.

${ }^{2}$ Limit of detection.

was elevated in both milk and plasma during coliform mastitis. Although the EPA vicinal diols 14,15- and 17,18-dihydroxyeicosatetraenoic acid (DiHETE) were increased in milk during coliform mastitis, significantly lower concentrations of the 14,15-DiHETE isomer were detected in plasma.

The nonenzymatic metabolites from AA (hydroxyeicosatetraenoic acids; 9- and 11-HETE) were abundant in milk, but not in plasma during mastitis. Consequently, nonenzymatic metabolites accounted for only 8 and $9 \%$ of the fraction of total oxylipids in milk and plasma, respectively (Table 6). The relative contribution of nonenzymatic auto-oxidation of LA into 9- and 13-HODE was not determined.

Relative contributions of metabolic pathways to oxylipid biosynthesis were assessed from ratios of metabolites of different pathways from the same PUFA substrate (Table 7). In both milk and plasma, the lack of differences between mastitis and control cows in the ratios 13-HODE to 9-HODE and 9- and 11-HETE to
15-HETE suggested lack of pathway preference for LA and ArA, respectively. However, there was a shift from epoxidation of ArA toward hydroxylation into 20HETE in milk during coliform mastitis.

Ratios representing the progressive metabolism of oxylipids such as the conversion of hydroxy oxylipids to ketone derivatives (HODE to oxoODE; HETE to oxoETE) and epoxides to vicinal diols (EpOME to DiHOME) were compared between groups (Table 8). Ratios suggesting greater (when $>1$ ) abundance of hydroxy metabolites were detected for both milk and plasma in all cows; however, only the ArA-derived metabolites in coliform mastitis milk samples and 13-HODE:13-oxoODE in plasma of control cows were significant. The within-group epoxide-to-vicinal diol ratios suggested abundant 12,13-EpOME $(>1)$ and lesser 9,10-EpOME $(<1)$ isomers in coliform mastitis cows and greater vicinal diols $(<1)$ in control cows. Numerical values of the epoxide-to-vicinal diol ratios were greater significantly in coliform than in control cows.

Table 3. Cyclooxygenase-derived oxylipids in milk and plasma from coliform mastitis $(\mathrm{n}=11)$ and midlactation control $(\mathrm{n}=13)$ cows (mean $\pm \mathrm{SEM} ; \mathrm{n} M)$

\begin{tabular}{|c|c|c|c|c|c|c|c|}
\hline \multirow[b]{2}{*}{ Sample } & \multirow[b]{2}{*}{ Oxylipid $^{1}$} & \multirow[b]{2}{*}{ Substrate $^{2}$} & \multicolumn{2}{|c|}{ Mastitis } & \multicolumn{2}{|c|}{ Control } & \multirow[b]{2}{*}{ Significance } \\
\hline & & & Mean & SEM & Mean & SEM & \\
\hline \multirow[t]{2}{*}{ Milk } & 6 -KetoPGF ${ }_{1 \alpha}$ & ArA & 1.19 & 0.36 & 0.44 & 0.00 & * \\
\hline & $\mathrm{PGE}_{2}$ & ArA & 2.28 & 0.56 & 0.05 & 0.06 & $* * *$ \\
\hline \multirow[t]{2}{*}{ Plasma } & 6 -KetoPGF ${ }_{1 \alpha}$ & ArA & 0.74 & 0.21 & 0.44 & 0.00 & $*$ \\
\hline & $\mathrm{PGE}_{2}$ & ArA & 0.24 & 0.06 & 0.20 & 0.07 & \\
\hline
\end{tabular}

${ }^{1}$ Data log-transformed; results expressed as geometric mean \pm SEM; $\mathrm{PGE}_{2}=$ prostaglandin $\mathrm{E}_{2} ; 6$-ketoPGF $\mathrm{P}_{1 \alpha}$ $=6$-keto prostaglandin $\mathrm{F}_{1 \alpha}$.

${ }^{2} \mathrm{ArA}=$ arachidonic acid.

$* P<0.05 ; * * * P<0.001$. 
Table 4. Lipoxygenase-derived oxylipids in milk and plasma from coliform mastitis $(\mathrm{n}=11)$ and mid-lactation control $(\mathrm{n}=13)$ cows $($ mean $\pm \mathrm{SEM} ; \mathrm{n} M)$

\begin{tabular}{|c|c|c|c|c|c|c|c|}
\hline \multirow[b]{2}{*}{ Sample } & \multirow[b]{2}{*}{ Oxylipid $^{1}$} & \multirow[b]{2}{*}{ Substrate $^{2}$} & \multicolumn{2}{|c|}{ Mastitis } & \multicolumn{2}{|c|}{ Control } & \multirow[b]{2}{*}{$P$-value } \\
\hline & & & Mean & SEM & Mean & SEM & \\
\hline \multirow[t]{12}{*}{ Milk } & 13-HODE & LA & 32.6 & 9.0 & 6.8 & 1.7 & $*$ \\
\hline & $9-\mathrm{HODE}^{3}$ & LA & 5.9 & 0.29 & 2.0 & 0.29 & $*$ \\
\hline & 13 -oxoODE ${ }^{3}$ & LA & 1.6 & 0.47 & 0.67 & 0.22 & \\
\hline & 9-oxoODE ${ }^{3}$ & LA & 1.3 & 0.40 & 0.67 & 0.37 & \\
\hline & 15 -oxoETE ${ }^{3}$ & ArA & 0.03 & 0.63 & 0.019 & 0.58 & \\
\hline & 5-oxoETE 3 & ArA & 0.04 & 0.80 & 0.010 & 0.61 & \\
\hline & $5-$ HETE $^{3}$ & ArA & 0.23 & 0.28 & 0.06 & 0.17 & $* * *$ \\
\hline & $\mathrm{LTB}_{4}{ }^{3}$ & ArA & 0.07 & 1.03 & 0.003 & 0.00 & $* *$ \\
\hline & $\mathrm{LXA}_{4}{ }^{3}$ & ArA & 0.09 & 0.45 & 0.01 & 0.3 & $* *$ \\
\hline & 15 -HETE ${ }^{3}$ & $\mathrm{ArA}$ & 3.0 & 0.26 & 0.07 & 0.27 & $* * *$ \\
\hline & $17-\mathrm{HDoHE}^{3}$ & DHA & 0.26 & 0.22 & 0.11 & 0.00 & \\
\hline & $\mathrm{RvD}_{2}{ }^{3}$ & DHA & 0.02 & 0.80 & 0.02 & 0.3 & \\
\hline \multirow[t]{10}{*}{ Plasma } & $13-\mathrm{HODE}^{3}$ & $\mathrm{LA}$ & 4.27 & 0.17 & 4.61 & 0.16 & \\
\hline & 9-HODE ${ }^{3}$ & LA & 1.34 & 0.21 & 1.41 & 0.20 & \\
\hline & 13-oxoODE & LA & 0.38 & 0.05 & 0.51 & 0.16 & \\
\hline & 9-oxoODE & LA & 0.86 & 0.17 & 1.3 & 0.34 & \\
\hline & 15-oxoETE & ArA & 0.02 & 0.005 & 0.03 & 0.01 & \\
\hline & 5-oxoETE & ArA & 0.01 & 0.002 & 0.02 & 0.005 & \\
\hline & $5-\mathrm{HETE}^{3}$ & $\mathrm{ArA}$ & 0.06 & 0.32 & 0.08 & 0.29 & \\
\hline & $\mathrm{LXA}_{4}^{3}$ & ArA & 0.01 & 0.12 & 0.04 & 0.41 & $* *$ \\
\hline & 15-HETE 3 & ArA & 0.36 & 0.30 & 0.20 & 0.27 & \\
\hline & $\mathrm{RvD}_{2}{ }^{3}$ & DHA & 0.003 & 0.02 & 0.10 & 0.08 & * \\
\hline
\end{tabular}

${ }^{1} \mathrm{HODE}=$ hydroxyoctadecadienoic acid; oxoODE $=$ oxooctadecadienoic acid; oxoETE $=$ oxoeicosatetraenoic acid; HETE = hydroxyeicosatetraenoic acid; $\mathrm{LTB}_{4}=$ leukotriene $\mathrm{B}_{4} ; \mathrm{LXA}_{4}=$ lipoxin $\mathrm{A}_{4}$, HDoHE $=$ hydroxydocosahexaenoic acid; $\mathrm{RvD}_{2}=$ resolvin $\mathrm{D}_{2}$.

${ }^{2} \mathrm{ArA}=$ arachidonic acid; $\mathrm{LA}=$ linoleic acid; $\mathrm{DHA}=$ docosahexaenoic acid.

${ }^{3}$ Data log-transformed, results expressed as geometric mean \pm SEM.

$* P<0.05 ;{ }^{* *} P<0.01 ;{ }^{* * *} P<0.001$.

Table 5. Cytochrome P450-derived oxylipids in milk and plasma from coliform mastitis $(\mathrm{n}=11)$ and midlactation control $(\mathrm{n}=13)$ cows (mean $\pm \mathrm{SEM} ; \mathrm{n} M)$

\begin{tabular}{|c|c|c|c|c|c|c|c|}
\hline \multirow[b]{2}{*}{ Sample } & \multirow[b]{2}{*}{ Oxylipid $^{1}$} & \multirow[b]{2}{*}{ Substrate $^{2}$} & \multicolumn{2}{|c|}{ Mastitis } & \multicolumn{2}{|c|}{ Control } & \multirow[b]{2}{*}{$P$-value } \\
\hline & & & Mean & SEM & Mean & SEM & \\
\hline \multirow[t]{9}{*}{ Milk } & $9,10-$ DiHOME $^{3}$ & LA & 2.0 & 0.54 & 6.6 & 0.17 & \\
\hline & $12,13-\mathrm{DiHOME}^{3}$ & LA & 2.7 & 0.45 & 5.0 & 0.37 & \\
\hline & 9,10-ЕpOME & LA & 0.95 & 0.20 & 0.46 & 0.05 & $*$ \\
\hline & 12,13-EpOME & LA & 2.3 & 0.57 & 0.40 & 0.06 & ** \\
\hline & $11,12-\mathrm{EET}^{3}$ & ArA & 0.02 & 0.28 & 0.01 & 0.00 & \\
\hline & $8,9-\mathrm{EET}^{3}$ & ArA & 0.05 & 0.43 & 0.02 & 0.00 & \\
\hline & $20-\mathrm{HETE}^{3}$ & ArA & 0.72 & 0.66 & 0.01 & 0.24 & $* * *$ \\
\hline & 14,15-DiHETE & EPA & 1.1 & 0.20 & 0.10 & 0.01 & $* * *$ \\
\hline & 17,18-DiHETE & EPA & 4.2 & 0.87 & 0.16 & 0.02 & $* *$ \\
\hline \multirow[t]{8}{*}{ Plasma } & 9,10-DiHOME & LA & 2.1 & 0.50 & 19.3 & 2.0 & $* * *$ \\
\hline & $12,13-\mathrm{DiHOME}^{3}$ & LA & 0.8 & 0.20 & 10.9 & 0.44 & $* * *$ \\
\hline & 9,10-ЕpOME & LA & 1.0 & 0.25 & 1.9 & 0.46 & \\
\hline & $12,13-\mathrm{EpOME}^{3}$ & $\mathrm{LA}$ & 1.0 & 0.26 & 1.8 & 0.24 & \\
\hline & 11,12-EET & ArA & 0.02 & 0.003 & 0.05 & 0.01 & $*$ \\
\hline & $20-\mathrm{HETE}^{3}$ & ArA & 0.53 & 0.31 & 0.24 & 0.15 & $*$ \\
\hline & 14,15-DiHETE & EPA & 1.1 & 0.19 & 1.5 & 0.16 & \\
\hline & 17,18-DiHETE & EPA & 8.0 & 1.3 & 19.6 & 3.3 & ** \\
\hline
\end{tabular}

${ }^{1}$ DiHOME $=$ dihydroxyoctadecenoic acid; EpOME = epoxyoctadecenoic acid; EET = epoxyeicosatrienoic acid; HETE $=$ hydroxyeicosatetraenoic acid; DiHETE $=$ dihydroxyeicosatrienoic acid

${ }^{2} \mathrm{LA}=$ linoleic acid; $\mathrm{ArA}=$ arachidonic acid; $\mathrm{EPA}=$ eicosapentaenoic acid.

${ }^{3}$ Data log-transformed, results expressed as geometric mean \pm SEM.

${ }^{*} P<0.05 ;{ }^{* *} P<0.01 ;{ }^{* * *} P<0.01$. 
Table 6. Nonenzymatic-derived oxylipids in milk and plasma from coliform mastitis $(\mathrm{n}=11)$ and midlactation control $(\mathrm{n}=13)$ cows (mean \pm SEM; $\mathrm{n} M)$

\begin{tabular}{|c|c|c|c|c|c|c|c|}
\hline \multirow[b]{2}{*}{ Sample } & \multirow[b]{2}{*}{ Oxylipid ${ }^{1}$} & \multirow[b]{2}{*}{ Substrate $^{2}$} & \multicolumn{2}{|c|}{ Mastitis } & \multicolumn{2}{|c|}{ Control } & \multirow[b]{2}{*}{$P$-value } \\
\hline & & & Mean & SEM & Mean & SEM & \\
\hline \multirow[t]{2}{*}{ Milk } & 11-HETE ${ }^{3}$ & ArA & 0.57 & 0.62 & 0.04 & 0.22 & $* *$ \\
\hline & 9-HETE ${ }^{3}$ & ArA & 0.10 & 0.61 & 0.02 & 0.36 & $* *$ \\
\hline \multirow[t]{2}{*}{ Plasma } & 11-HETE & ArA & 0.20 & 0.05 & 0.14 & 0.02 & \\
\hline & 9-HETE & ArA & 0.06 & 0.02 & 0.03 & 0.004 & \\
\hline
\end{tabular}

${ }^{1} \mathrm{HETE}=$ hydroxyeicosatetraenoic acid.

${ }^{2} \mathrm{ArA}=$ arachidonic acid.

${ }^{3}$ Data log-transformed, results expressed as geometric mean \pm SEM.

$* * P<0.01$.

Table 7. Milk and plasma oxylipids in coliform mastitis $(\mathrm{n}=11)$ and mid-lactation control $(\mathrm{n}=13)$ cows expressed as ratios of select pathways based on substrate

\begin{tabular}{|c|c|c|c|c|c|}
\hline Sample & Ratio $^{1}$ & Substrate $^{2}$ & Mastitis cows & Control cows & $P$-value \\
\hline \multirow[t]{3}{*}{ Milk } & $13-\mathrm{HODE}^{3} / 9-\mathrm{HODE}^{4}$ & LA & $4.12 \pm 0.13$ & $2.60 \pm 0.26$ & \multirow{4}{*}{$* *$} \\
\hline & Sum EET/20-HETE & ArA & $0.10 \pm 0.51$ & $5.32 \pm 0.71$ & \\
\hline & $(9-\mathrm{HETE}+11 \text {-HETE })^{5} / 15$-HETE ${ }^{3}$ & ArA & $0.25 \pm 0.65$ & $0.84 \pm 0.12$ & \\
\hline Plasma & (9-HETE + 11-HETE)/15-HETE & ArA & $0.59 \pm 0.08$ & $0.60 \pm 0.07$ & \\
\hline
\end{tabular}

${ }^{1} \mathrm{HODE}=$ hydroxyoctadecadienoic acid; EET $=$ epoxyeicosatrienoic acid; HETE $=$ hydroxyeicosatetraenoic acid.

${ }^{2} \mathrm{ArA}=$ arachidonic acid; LA = linoleic acid.

${ }^{3}$ Predominantly enzyme derived.

${ }^{4}$ Both enzymatic and nonenzymatic derived.

${ }^{5}$ Predominantly nonenzymatic derived.

${ }^{* *} P<0.01$.

Table 8. Milk and plasma oxylipids in coliform mastitis $(\mathrm{n}=11)$ and mid-lactation control $(\mathrm{n}=13)$ cows expressed as ratios of select upstream:downstream metabolites based on substrate

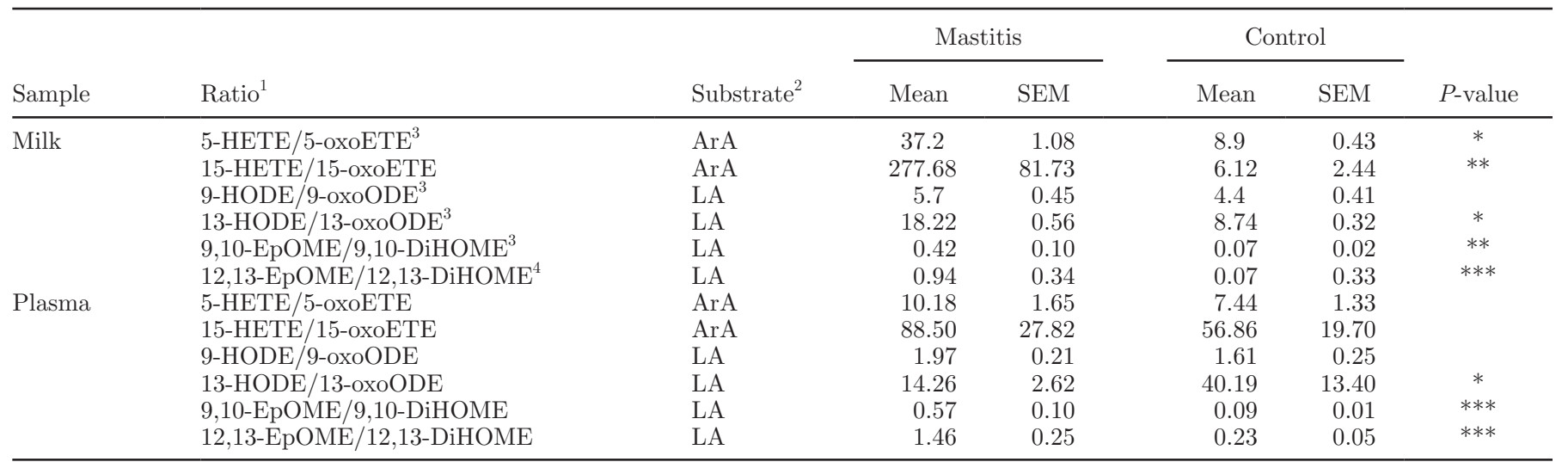

${ }^{1} \mathrm{HETE}=$ hydroxyeicosatetraenoic acid; oxoETE $=$ oxoeicosatetraenoic acid; HODE $=$ hydroxyoctadecadienoic acid; oxoODE $=$ oxooctadecadienoic acid; EpOME = epoxyoctadecenoic acid; DiHOME = dihydroxyoctadecenoic acid.

${ }^{2} \mathrm{ArA}=$ arachidonic acid; LA = linoleic acid.

${ }^{4}$ Square-root transformed data reported as geometric mean \pm SEM.

${ }^{4} \mathrm{Log}$ transformed data reported as geometric mean \pm SEM.

${ }^{*} P<0.05 ;{ }^{* *} P<0.01 ;{ }^{* * *} P<0.001$. 
Table 9. Correlations between FA substrates and their oxylipid metabolites in milk and plasma from coliform mastitis cows

\begin{tabular}{lccccccc}
\hline & \multicolumn{2}{c}{ Milk } & & \multicolumn{2}{c}{ Plasma } \\
\cline { 2 - 4 } \cline { 5 - 7 } Substrate and metabolite & & $\mathrm{r}$ & $P$-value & & $\mathrm{r}$ & $P$-value \\
\hline ArA vs. 15-oxoETE & 0.921 & $* *$ & & & \\
EPA vs. 14,15-DiHETE & & & & 0.863 & $* *$ \\
EPA vs. 17,18-DiHETE & & & & 0.756 & $*$ \\
\hline
\end{tabular}

${ }^{1} \mathrm{ArA}=$ arachidonic acid; oxoETE $=$ oxoeicosatetraenoic; $\mathrm{EPA}=$ eicosapentaenoic acid; DiHETE $=$ dihydroxyeicosatrienoic acid

${ }^{*} P<0.05 ; * * P<0.01$

Several significant correlations were detected among quantified metabolites (FA, FA and oxylipids, oxylipid to oxylipid) in milk and plasma from coliform mastitis cows (Tables 9, 10, and 11). Interestingly, no correlations could be detected for several metabolites between the milk and plasma samples, especially in the coliform mastitis group. Endocannabinoid metabolites derived from ArA and DHA only were detected with significantly higher concentrations of arachidonyl ethanolamide (mastitis, $1.5 \pm 0.2 \mathrm{n} M$ vs. control $0.07 \pm 0.01$ $\mathrm{n} M ; \quad P<0.0001)$ and docosahexanoyl ethanolamide (mastitis, $1.5 \pm 0.05 \mathrm{n} M$ vs. control $1.1 \pm 0.004 \mathrm{n} M$; $P<0.001$ ) in milk, but not in plasma, during coliform mastitis.

\section{DISCUSSION}

Polyunsaturated fatty acids are essential substrates that play a critical role in the synthesis of oxylipids during health and inflammatory processes. The elevations of all PUFA assessed in milk in this study agree with previous findings of increased LA, ArA, and EPA in milk from bovine mastitis (Atroshi et al., 1989b). Mastitis in humans is also associated with increased long-chain FA in milk (Hunt et al., 2013). The increased
PUFA suggest abundance of oxylipid precursor substrates whose sources may include increased lipolysis, dietary lipids, and de novo biosynthesis from essential FA. Although sources of FA were not evaluated in this study, increased lipolysis related to elevated tumor necrosis factor $\alpha$ ( $\mathbf{T N F} \boldsymbol{\alpha})$, may have contributed to increased PUFA substrate (Hoeben et al., 2000). For example, previous studies showed that plasma $\mathrm{TNF} \alpha$ concentrations increase significantly with bovine coliform mastitis (Sordillo and Peel, 1992). Experimental injection of $\mathrm{TNF} \alpha$ and the associated decrease in DMI increased adipose tissue lipolysis in cows (Kushibiki et al., 2003). Although plasma NEFA, an indicator of lipolysis, were not measured in this study, increased lipolysis could be supported by significant elevations in oleic acid in this study, a known abundant component of plasma NEFA in dairy cows during times of increased lipolysis (Contreras and Sordillo, 2011).

The simultaneous evaluation of metabolites in milk and plasma during coliform mastitis showed substantial differences in oxylipid profiles even with the presence of systemic disease. Similarly, mice with LPS-induced sepsis demonstrated different oxylipid profiles among various tissue locations (Balvers et al., 2012). Consequently, oxylipid concentrations in one biological sample cannot be used to infer oxylipid profiles in a different anatomic area. The lack of correlations in concentrations of several oxylipids between milk and plasma during mastitis (Table 11) suggests that the microenvironment of the affected tissues can greatly influence oxylipid biosynthesis. Concentrations of milk and plasma PUFA substrates differed during coliform mastitis and can be explained by several factors. First, milk production decreases precipitously during coliform mastitis, resulting in elevated concentrations of milk components, including FFA (Shuster et al., 1991). Second, the disruption of the blood mammary endothelial

Table 10. Correlations between degree of metabolism for select oxylipids in milk and plasma from coliform mastitis cows

\begin{tabular}{|c|c|c|c|c|c|}
\hline \multirow[b]{2}{*}{ Substrate $^{1}$} & \multirow[b]{2}{*}{ Degree of metabolism ${ }^{2}$} & \multicolumn{2}{|c|}{ Milk } & \multicolumn{2}{|c|}{ Plasma } \\
\hline & & $\mathrm{r}$ & $P$-value & $\mathrm{r}$ & $P$-value \\
\hline LA & 13-HODE vs. 9-HODE & 0.864 & * & 0.834 & $*$ \\
\hline LA & 13-HODE vs. 13 -oxoODE & 0.736 & * & 0.26 & NS \\
\hline LA & 9-HODE vs. 9-oxoODE & 0.791 & * & 0.882 & $* *$ \\
\hline LA & 9,10-DiHOME vs. 9,10-EpOME & 0.724 & $*$ & 0.387 & NS \\
\hline LA & 12,13-EpOME vs. 12,13 -DiHOME & 0.382 & NS & 0.75 & * \\
\hline ArA & 5-HETE vs. 5-oxoETE & 0.639 & $*$ & 0.678 & $*$ \\
\hline ArA & 15-HETE vs. 15-oxoETE & 0.639 & NS & 0.531 & NS \\
\hline
\end{tabular}


Table 11. Correlations between fatty acid:fatty acid substrate and oxylipid:oxylipid between samples (e.g., milk LA correlated with plasma LA) within each experimental groups

\begin{tabular}{|c|c|c|c|c|c|}
\hline \multirow[b]{2}{*}{ Substrate $^{1}$} & \multirow{2}{*}{$\begin{array}{l}\text { Oxylipid } \\
\text { metabolite }\end{array}$} & \multicolumn{2}{|c|}{ Mastitis group } & \multicolumn{2}{|c|}{ Control group } \\
\hline & & $\mathrm{r}$ & $P$-value & $\mathrm{r}$ & $P$-value \\
\hline LA & & & & 0.843 & $* * *$ \\
\hline ArA & & & & 0.903 & $* * *$ \\
\hline EPA & & 0.789 & ** & 0.755 & $* *$ \\
\hline LA & 13-HODE & & & 0.844 & $* * *$ \\
\hline $\mathrm{LA}$ & 9-oxoODE & & & 0.976 & $* * *$ \\
\hline LA & 13-oxoODE & & & 0.793 & $* *$ \\
\hline LA & 12,13-ЕpOME & & & 0.753 & ** \\
\hline $\mathrm{LA}$ & 9,10-DiHOME & 0.730 & $*$ & & \\
\hline LA & 12,13-DiHOME & 0.906 & $* * *$ & 0.841 & $* * *$ \\
\hline ArA & 15-HETE & 0.751 & $* *$ & & \\
\hline $\mathrm{ArA}$ & 15-oxoETE & & & 0.845 & $* *$ \\
\hline ArA & $2-\mathrm{AG}$ & & & 0.758 & $* *$ \\
\hline
\end{tabular}

${ }^{1} \mathrm{LA}=$ linoleic acid; $\mathrm{Ar} \mathrm{A}$ = arachidonic acid; $\mathrm{EPA}=$ eicosapentaenoic acid.

${ }^{2} \mathrm{HODE}=$ hydroxyoctadecadienoic acid; oxoODE = oxooctadecadienoic acid; EpOME $=$ epoxyoctadecenoic acid; DiHOME = dihydroxyoctadecenoic acid; HETE = hydroxyeicosatetraenoic acid; oxoETE = oxoeicosatetraenoic acid; $\mathrm{AG}=$ arachidonoyl glycerol.

${ }^{*} P<0.05 ;{ }^{* *} P<0.01 ;{ }^{* * *} P<0.001$.

barrier and increased blood flow to the mammary gland during coliform mastitis could result in increased transfer of long-chain FA into the mammary gland (Wenz et al., 2001). For example, previous studies in mice with LPS-induced peritonitis showed that increased n-3 fatty acids intravenously pre-infused were detected in peritoneal exudates (Kasuga et al., 2008). Increasing plasma concentrations of select PUFA types such as the n-3 FA may be a direct source of PUFA for localized inflammatory sites. Thus, plasma PUFA may be increased by their dietary supplementation or precursor essential FA such as LA and $\alpha$-linoleic acid to support de novo biosynthesis of PUFA.

The variety of oxylipids expressed in both milk and plasma in this study represented some of the well-known enzymatic and nonenzymatic oxylipid biosynthetic pathways. Earlier studies on bovine coliform mastitis reported a few select prostanoids including $\mathrm{PGE}_{2}$, $\mathrm{PGF}_{2 \alpha}$, and thromboxane $\mathrm{B}_{2}$ in milk using immunoassay based detection techniques (Atroshi et al., 1989a). In the current study, the use of LC-MS/MS provided a more robust methodology to identify an expanded oxylipid network during acute bovine coliform mastitis.

Oxylipids generated from the COX pathway in the current study were represented only by $\mathrm{PGE}_{2}$ and the inactive downstream metabolite of $\mathrm{PGI}_{2}, 6$-ketoPGF $\mathrm{F}_{1 \alpha}$. Both $\mathrm{PGI}_{2}$ and $\mathrm{PGE}_{2}$ are produced by constitutive COX-1 and inducible COX-2 isoforms and are important for the vasodynamic responses during initial stages of inflammation (Bulger and Maier, 2000). In addition to maintaining basal prostanoid production, COX1 isoforms are responsible for the initial prostanoid synthesis during inflammation before induction of the transcriptionally and translationally dependent COX-2 isoform (Pober and Sessa, 2007). Previous experimental and natural bovine coliform mastitis studies reported increased concentrations of $\mathrm{PGE}_{2}, \mathrm{PGI}_{2}, \mathrm{PGF}_{2 \alpha}$, and thromboxane $\mathrm{B}_{2}$. Inhibition of COX enzymes using nonsteroidal anti-inflammatory drugs (NSAID) reduces prostanoid and thromboxane concentrations, with subsequent improved clinical signs (Anderson et al., 1986). Use of NSAID in veterinary medicine, however, is associated with complications such as abomasal ulceration and renal toxicity (Anderson and Muir, 2005). Defining the variety and temporal generation of COX-derived oxylipids during coliform mastitis may identify optimal times for pharmacologic inhibition of COX enzymes. In acute bovine coliform mastitis, for example, early NSAID use may not be optimal as oxylipid products of COX enzymes mediate crucial processes during early stages of acute inflammation.

The LOX-derived metabolites accounted for the majority of oxylipids detected in the present study. Several lines of evidence showed that LOX generates both pro- and anti-inflammatory oxylipids. For example, development of atherosclerosis in humans is associated with increased 15LOX mRNA expression and hydroxy metabolites including 15-HETE and 9- and 13-HODE (Gertow et al., 2011). Several oxylipids, including lipoxin $\mathrm{A}_{4}$, resolvins, protectins, and maresins in several murine models of sepsis, are associated with shorter time to inflammation resolution and improved survival (Serhan et al., 2008). In dairy cows, 15LOX1 gene expression was increased in mammary gland tissues during the periparturient period, suggesting a potential contribution to oxidative stress in transition cows (Aitken et 
al., 2009). Oxidative stress was suggested as contributing to predisposing periparturient cows to dysregulated inflammatory conditions including mastitis (Sordillo and Mavangira, 2014). Nonspecific inhibition of LOX in combination with flunixin meglumine, a COX inhibitor, was associated with improved bovine mammary gland inflammation (Rose et al., 1991). Taken together, these data demonstrate the need to clearly define the role of LOX-derived oxylipids in the pathophysiology of coliform mastitis to explore potential targets and optimal times for therapy or interventions.

The metabolism of PUFA through CYP enzymes showed significant elevations in various epoxides of ArA, LA, and EPA. Several epoxide metabolites were identified as unexplored targets for therapy with potent anti-inflammatory effects (Morisseau and Hammock, 2013). For example, with LPS-induced peritonitis, inhibiting hydration of epoxides decreased pro-inflammatory cytokines, abrogated hypotension, and diminished mortality compared with control mice (Schmelzer et al., 2005). Furthermore, pro-inflammatory metabolites of COX and LOX pathways such as $\mathrm{PGE}_{2}$ and 5-HETE, respectively, were decreased, suggesting an indirect influence of CYP epoxides on acute inflammatory pathways (Schmelzer et al., 2005). Conversely, CYP hydroxylation of ArA produces 20-HETE, a potent hypertensive oxylipid during inflammation (Konkel and Schunck, 2011). Epoxides of LA origin are associated with acute respiratory distress syndrome following sepsis in humans (Konkel and Schunck, 2011), suggesting that FA substrate and relative abundance of their derived oxylipids may affect the inflammatory phenotype. Defining the relative contributions of CYP derived epoxides from different PUFA is critical to balance between the beneficial anti-inflammatory species and the pro-inflammatory 20-HETE and LA epoxides. The apparent shift from epoxidation into hydroxylation of ArA (Table 7) in the current study suggests a contribution of pro-inflammatory 20-HETE to the acute inflammatory phase during bovine coliform mastitis. The ability of epoxides to downregulate pro-inflammatory metabolites from other biosynthetic pathways may make them particularly attractive because of a multimodal mechanism that may be very effective at resolving inflammation.

Several PUFA metabolites exhibit different levels of metabolism producing distinct oxylipid species with specific effects on the inflammatory process. For example, LA is initially oxygenated to hydroperoxy acids (9- and 13-HPODE) that are subsequently reduced by peroxidases to hydroxy acids (9- and 13-HODE). Dehydrogenase enzymes eventually convert the hydroxyacid metabolites into ketone derivatives (9- and 13-oxoODE). The hydroperoxy oxylipid 13-HPODE activates the pro-inflammatory transcription factor $\mathrm{NF} \kappa \mathrm{B}$ in vascular smooth muscle cells (Natarajan et al., 2001). In addition, another hydroperoxy metabolite, 15HPETE, mediates inflammation and apoptosis in bovine aortic endothelial cells (Sordillo et al., 2005). Hydroxy metabolites (HODE and ArA-derived HETE) are associated with either pro- or anti-inflammatory states in cardiovascular and other diseases (Kuhn et al., 2015). The ketone derivatives have predominantly anti-inflammatory effects. For example, 13-oxoODE reduces pro-inflammatory IL-8 through peroxisome proliferator-activated receptor gamma activation in human colonic epithelial cells (Altmann et al., 2007). Together, these data suggest that the degree of PUFA catabolism during inflammation may affect the duration, phenotype, and outcome of inflammatory process. Although upstream oxylipids were positively correlated with their downstream derivatives in the current study (Tables 9 and 10), the abundance of ArA- and LAderived hydroxy oxylipids suggests an overproduction or decreased dehydrogenation to the ketone derivatives, indicating a pro-inflammatory oxylipid profile. Studying the temporal patterns of the degree of metabolism of PUFA and the specific effects of their oxylipid metabolites during inflammation may uncover targets for enhancement or blockade of metabolic pathways to modulate inflammation.

The roles for endocannabinoid metabolites from ArA and DHA that accumulated during coliform mastitis are not immediately clear. In a rat model of LPS-induced uveitis, activation of cannabinoid CB2 receptors was associated with reduction in the pro-inflammatory transcription factors, pro-inflammatory cytokines, and leukocyte endothelial adhesion (Toguri et al., 2014). The endocannabinoid system was reviewed recently as a potential inflammation modulatory target in various human diseases (Zubrzycki et al., 2014a,b). In cows, endocannabinoids were detected in milk from healthy animals (Gouveia-Figueira and Nording, 2014). Further investigations may be useful to determine the presence and influence of cannabinoid receptors on mammary gland inflammation.

\section{CONCLUSIONS}

In conclusion, oxylipid generation during acute bovine coliform mastitis is influenced by substrate availability, multiple biosynthetic pathways, and different degrees of metabolism. The use of LC-MS/MS offers a sensitive and specific technique that can be utilized to evaluate novel targets in oxylipid biosynthesis for diagnostic and therapeutic interventions in inflammatory conditions, including coliform mastitis. Additionally, biomarkers that reflect oxylipid profiles and inflammatory pheno- 
type during disease can be developed. The detection of several localized changes in oxylipid biosynthesis in the presence of systemic disease suggests focusing specifically on the mammary gland environment in developing and evaluating interventions to modulate inflammation during mastitis.

\section{ACKNOWLEDGMENTS}

The authors acknowledge the staff and resources at the Michigan State Research Technology Support Facility Mass Spectrometry and Metabolomics Core (East Lansing), especially Scott Smith. The Waters Xevo TQ-S mass spectrometer was purchased using funds from the Great Lakes Fishery Commission (Ann Arbor, MI). The authors thank Sasha Kravchenko at the Michigan State Plant, Soil and Microbial Sciences department for assistance with statistical analyses. The authors thank Louis M. Neuder, and Jill Brester (Michigan State University, Teaching Center for Dairy Professionals) and the owners and staff at the participating dairy. This work was funded through the Michigan AgBioResearch project MICL02143 and through grant 2011-67015-30179 from the Agriculture and Food Research Initiative Competitive Grants Programs of the USDA National Institute for Food and Agriculture (Washington, DC).

\section{REFERENCES}

Aitken, S. L., E. L. Karcher, P. Rezamand, J. C. Gandy, M. J. VandeHaar, A. V. Capuco, and L. M. Sordillo. 2009. Evaluation of antioxidant and proinflammatory gene expression in bovine mammary tissue during the periparturient period. J. Dairy Sci. 92:589-598. http://dx.doi.org/10.3168/jds.2008-1551.

Altmann, R., M. Hausmann, T. Spottl, M. Gruber, A. W. Bull, K. Menzel, D. Vogl, H. Herfarth, J. Scholmerich, W. Falk, and G. Rogler. 2007. 13-Oxo-ODE is an endogenous ligand for PPARgamma in human colonic epithelial cells. Biochem. Pharmacol. 74:612-622. http://dx.doi.org/10.1016/j.bcp.2007.05.027.

Anderson, D. E., and W. W. Muir. 2005. Pain management in ruminants. Vet. Clin. North Am. Food Anim. Pract. 21:19-31. http:// dx.doi.org/10.1016/j.cvfa.2014.12.008.

Anderson, K. L., H. Kindahl, A. R. Smith, L. E. Davis, and B. K. Gustafsson. 1986. Endotoxin-induced bovine mastitis: ArA metabolites in milk and plasma and effect of flunixin meglumine. Am. J. Vet. Res. 47:1373-1377.

Atroshi, F., A. Rizzo, R. Kangasniemi, S. Sankari, T. Tyopponen, T. Osterman, and J. Parantainen. 1989a. Role of plasma fatty acids, prostaglandins and antioxidant balance in bovine mastitis. Zentralbl. Veterinarmed. A 36:702-711.

Atroshi, F., A. Rizzo, T. Osterman, and J. Parantainen. 1989b. Free fatty acids and lipid peroxidation in normal and mastitic bovine milk. Zentralbl. Veterinarmed. A 36:321-330.

Balvers, M. G., K. C. Verhoeckx, J. Meijerink, S. Bijlsma, C. M. Rubingh, H. M. Wortelboer, and R. F. Witkamp. 2012. Time-dependent effect of in vivo inflammation on eicosanoid and endocannabinoid levels in plasma, liver, ileum and adipose tissue in C57BL/6 mice fed a fish-oil diet. Int. Immunopharmacol. 13:204-214. http://dx.doi.org/10.1016/j.intimp.2012.03.022.

Bernabucci, U., B. Ronchi, N. Lacetera, and A. Nardone. 2005. Influence of body condition score on relationships between meta- bolic status and oxidative stress in periparturient dairy cows. J. Dairy Sci. 88:2017-2026. http://dx.doi.org/10.3168/jds.S00220302(05)72878-2.

Buczynski, M. W., D. S. Dumlao, and E. A. Dennis. 2009. Thematic Review Series: Proteomics. An integrated omics analysis of eicosanoid biology. J. Lipid Res. 50:1015-1038. http://dx.doi. org/10.1194/jlr.R900004-JLR200.

Bulger, E. M., and R. V. Maier. 2000. Lipid mediators in the pathophysiology of critical illness. Crit. Care Med. 28(Suppl):N27-N36.

Calder, P. C. 2008. The relationship between the fatty acid composition of immune cells and their function. Prostaglandins Leukot. Essent. Fatty Acids 79:101-108. http://dx.doi.org/10.1016/j. plefa.2008.09.016.

Childs, S., A. A. Hennessy, J. M. Sreenan, D. C. Wathes, Z. Cheng, C. Stanton, M. G. Diskin, and D. A. Kenny. 2008. Effect of level of dietary n-3 polyunsaturated fatty acid supplementation on systemic and tissue fatty acid concentrations and on selected reproductive variables in cattle. Theriogenology 70:595-611. http://dx.doi. org/10.1016/j.theriogenology.2008.04.002.

Contreras, G. A., and L. M. Sordillo. 2011. Lipid mobilization and inflammatory responses during the transition period of dairy cows. Comp. Immunol. Microbiol. Infect. Dis. 34:281-289. http:// dx.doi.org/10.1016/j.cimid.2011.01.004.

Corl, C. M., J. Gandy, and L. Sordillo. 2008. Platelet activating factor production and proinflammatory gene expression in endotoxin-challenged bovine mammary endothelial cells. J. Dairy Sci. 91:3067-3078. http://dx.doi.org/10.3168/jds.2008-1066.

Erskine, R. J., R. Eberhart, L. Hutchinson, S. Spencer, and M. Campbell. 1988. Incidence and types of clinical mastitis in dairy herds with high and low somatic cell counts. J. Am. Vet. Med. Assoc. 192:761-765

Gertow, K., E. Nobili, L. Folkersen, J. W. Newman, T. L. Pedersen, J Ekstrand, J. Swedenborg, H. Kuhn, C. E. Wheelock, G. K. Hansson, U. Hedin, J. Z. Haeggstrom, and A. Gabrielsen. 2011. 12- and 15-lipoxygenases in human carotid atherosclerotic lesions: Associations with cerebrovascular symptoms. Atherosclerosis 215:411416. http://dx.doi.org/10.1016/j.atherosclerosis.2011.01.015.

Gouveia-Figueira, S., and M. L. Nording. 2014. Development and validation of a sensitive UPLC-ESI-MS/MS method for the simultaneous quantification of 15 endocannabinoids and related compounds in milk and other biofluids. Anal. Chem. 86:1186-1195. http:// dx.doi.org/10.1021/ac403352e.

Hoeben, D., C. Burvenich, E. Trevisi, G. Bertoni, J. Hamann, R. M. Bruckmaier, and J. W. Blum. 2000. Role of endotoxin and TNFalpha in the pathogenesis of experimentally induced coliform mastitis in periparturient cows. J. Dairy Res. 67:503-514.

Hogan, J., and K. L. Smith. 2003. Coliform mastitis. Vet. Res. 34:507-519. http://dx.doi.org/10.1051/vetres:2003022.

Hogan, J. S., R. N. Gonzales, R. J. Harmon, S. C. Nickerson, S. P. Oliver, J. W. Pankey, and K. L. Smith. 1999. Laboratory Handbook on Bovine Mastitis. Rev. ed. National Mastitis Council Inc., Madison, WI.

Hunt, K. M., J. E. Williams, B. Shafii, M. K. Hunt, R. Behre, R. Ting, M. K. McGuire, and M. A. McGuire. 2013. Mastitis is associated with increased free fatty acids, somatic cell count, and interleukin-8 concentrations in human milk. Breastfeed. Med. 8:105-110. http://dx.doi.org/10.1089/bfm.2011.0141.

Kasuga, K., R. Yang, T. F. Porter, N. Agrawal, N. A. Petasis, D. Irimia, M. Toner, and C. N. Serhan. 2008. Rapid appearance of resolvin precursors in inflammatory exudates: novel mechanisms in resolution. J. Immunol. 181:8677-8687. http://dx.doi.org/10.4049/ jimmunol.181.12.8677.

Konkel, A., and W.-H. Schunck. 2011. Role of cytochrome P450 enzymes in the bioactivation of polyunsaturated fatty acids. Biochim. Biophys. Acta 1814:210-222. http://dx.doi.org/10.1016/j. bbapap.2010.09.009.

Kuhn, H., S. Banthiya, and K. van Leyen. 2015. Mammalian lipoxygenases and their biological relevance. Biochim. Biophys. Acta 1851:308-330. http://dx.doi.org/10.1016/j.bbalip.2014.10.002.

Kushibiki, S., K. Hodate, H. Shingu, Y. Obara, E. Touno, M. Shinoda, and Y. Yokomizo. 2003. Metabolic and lactational responses 
during recombinant bovine tumor necrosis factor-alpha treatment in lactating cows. J. Dairy Sci. 86:819-827. http://dx.doi. org/10.3168/jds.S0022-0302(03)73664-9.

Milne, G. L., H. Yin, K. D. Hardy, S. S. Davies, and L. J. Roberts. 2011. Isoprostane generation and function. Chem. Rev. 111:59735996. http://dx.doi.org/10.1021/cr200160h.

Morisseau, C., and B. D. Hammock. 2013. Impact of soluble epoxide hydrolase and epoxyeicosanoids on human health. Annu. Rev Pharmacol. Toxicol. 53:37-58. http://dx.doi.org/10.1146/annurev-pharmtox-011112-140244.

Murakami, M., Y. Taketomi, Y. Miki, H. Sato, T. Hirabayashi, and K. Yamamoto. 2011. Recent progress in phospholipase A(2) research: From cells to animals to humans. Prog. Lipid Res. 50:152-192. http://dx.doi.org/10.1016/j.plipres.2010.12.001.

Natarajan, R., M. A. Reddy, K. U. Malik, S. Fatima, and B. V. Khan 2001. Signaling mechanisms of nuclear factor-kappa b-mediated activation of inflammatory genes by 13-hydroperoxyoctadecadienoic acid in cultured vascular smooth muscle cells. Arterioscler. Thromb. Vasc. Biol. 21:1408-1413. http://dx.doi.org/10.1161/ hq0901.095278.

O'Donnell, V. B., B. Maskrey, and G. W. Taylor. 2009. Eicosanoids: generation and detection in mammalian cells. Methods Mol. Biol. 462:5-23.

Oliveira, L., C. Hulland, and P. Ruegg. 2013. Characterization of clinical mastitis occurring in cows on 50 large dairy herds in Wisconsin. J. Dairy Sci. 96:7538-7549. http://dx.doi.org/10.3168/jds.20126078.

Pober, J. S., and W. C. Sessa. 2007. Evolving functions of endothelial cells in inflammation. Nat. Rev. Immunol. 7:803-815. http:// dx.doi.org/10.1038/nri2171.

Rose, D. M., S. N. Giri, J. S. Cullor, and R. B. Bushnell. 1991. The combined use of lipoxygenase and cyclooxygenase inhibitors in Klebsiella pneumoniae-induced bovine mastitis. Zentralbl. Veterinarmed. A 38:99-106.

Rosenthal, M. D., B. A. Rzigalinski, P. F. Blackmore, and R. C. Franson. 1995. Cellular regulation of arachidonate mobilization and metabolism. Prostaglandins Leukot. Essent. Fatty Acids 52:9398.

Schmelzer, K. R., L. Kubala, J. W. Newman, I.-H. Kim, J. P. Eiserich, and B. D. Hammock. 2005. Soluble epoxide hydrolase is a therapeutic target for acute inflammation. Proc. Natl. Acad. Sci. USA 102:9772-9777. http://dx.doi.org/10.1073/pnas.0503279102.

Serhan, C. N., N. Chiang, and T. E. Van Dyke. 2008. Resolving inflammation: Dual anti-inflammatory and pro-resolution lipid mediators. Nat. Rev. Immunol. 8:349-361. http://dx.doi.org/10.1038/ nri2294.

Shuster, D. E., R. J. Harmon, J. A. Jackson, and R. W. Hemken. 1991. Suppression of milk production during endotoxin-induced mastitis. J. Dairy Sci. 74:3763-3774. http://dx.doi.org/10.3168/jds.S00220302(91)78568-8.
Sordillo, L., and V. Mavangira. 2014. The nexus between nutrient metabolism, oxidative stress and inflammation in transition cows. Anim. Prod. Sci. 54:1204-1214. http://dx.doi.org/10.1071/ AN14503.

Sordillo, L. M., and J. Peel. 1992. Effect of interferon- $\gamma$ on the production of tumor necrosis factor during acute Escherichia coli mastitis. J. Dairy Sci. 75:2119-2125. http://dx.doi.org/10.3168/jds.S00220302(92)77971-5.

Sordillo, L. M., G. A. Contreras, and S. L. Aitken. 2009. Metabolic factors affecting the inflammatory response of periparturient dairy cows. Anim. Health Res. Rev. 10:53-63. http://dx.doi. org/10.1017/S1466252309990016

Sordillo, L. M., J. A. Weaver, Y.-Z. Cao, C. Corl, M. J. Sylte, and I. K. Mullarky. 2005. Enhanced 15-HPETE production during oxidant stress induces apoptosis of endothelial cells. Prostaglandins Other Lipid Mediat. 76:19-34. http://dx.doi.org/10.1016/j. prostaglandins.2004.10.007.

Spector, A. A., X. Fang, G. D. Snyder, and N. L. Weintraub. 2004. Epoxyeicosatrienoic acids (EETs): metabolism and biochemical function. Prog. Lipid Res. 43:55-90. http://dx.doi.org/10.1016/ S0163-7827(03)00049-3.

Tam, V. C. 2013. Lipidomic profiling of bioactive lipids by mass spectrometry during microbial infections. Semin. Immunol. 25:240248. http://dx.doi.org/10.1016/j.smim.2013.08.006.

Toguri, J. T., C. Lehmann, R. B. Laprairie, A. M. Szczesniak, J. Zhou, E. M. Denovan-Wright, and M. E. Kelly. 2014. Anti-inflammatory effects of cannabinoid $\mathrm{CB}(2)$ receptor activation in endotoxin-induced uveitis. Br. J. Pharmacol. 171:1448-1461. http://dx.doi. org $/ 10.1111 /$ bph. 12545

Vangroenweghe, F., I. Lamote, and C. Burvenich. 2005. Physiology of the periparturient period and its relation to severity of clinical mastitis. Domest. Anim. Endocrinol. 29:283-293. http://dx.doi. org/10.1016/j.domaniend.2005.02.016.

Wenz, J. R., G. M. Barrington, F. B. Garry, K. D. McSweeney, R. P. Dinsmore, G. Goodell, and R. J. Callan. 2001. Bacteremia associated with naturally occurring acute coliform mastitis in dairy cows. J. Am. Vet. Med. Assoc. 219:976-981. http://dx.doi.org/10.2460/ javma.2001.219.976.

Wu, G., J. M. Lu, W. A. van der Donk, R. J. Kulmacz, and A. L. Tsai 2011. Cyclooxygenase reaction mechanism of prostaglandin $\mathrm{H}$ synthase from deuterium kinetic isotope effects. J. Inorg. Biochem. 105:382-390. http://dx.doi.org/10.1016/j.jinorgbio.2010.11.015.

Zubrzycki, M., A. Liebold, A. Janecka, and M. Zubrzycka. 2014a. A new face of endocannabinoids in pharmacotherapy. Part I: protective role of endocannabinoids in hypertension and myocardial infarction. J. Physiol. Pharmacol. 65:171-181.

Zubrzycki, M., A. Liebold, A. Janecka, and M. Zubrzycka. 2014b. A new face of endocannabinoids in pharmacotherapy. Part II: role of endocannabinoids in inflammation-derived cardiovascular diseases. J. Physiol. Pharmacol. 65:183-191. 
APPENDIX

Table A1. Optimized multiple reaction monitoring parameters for metabolites

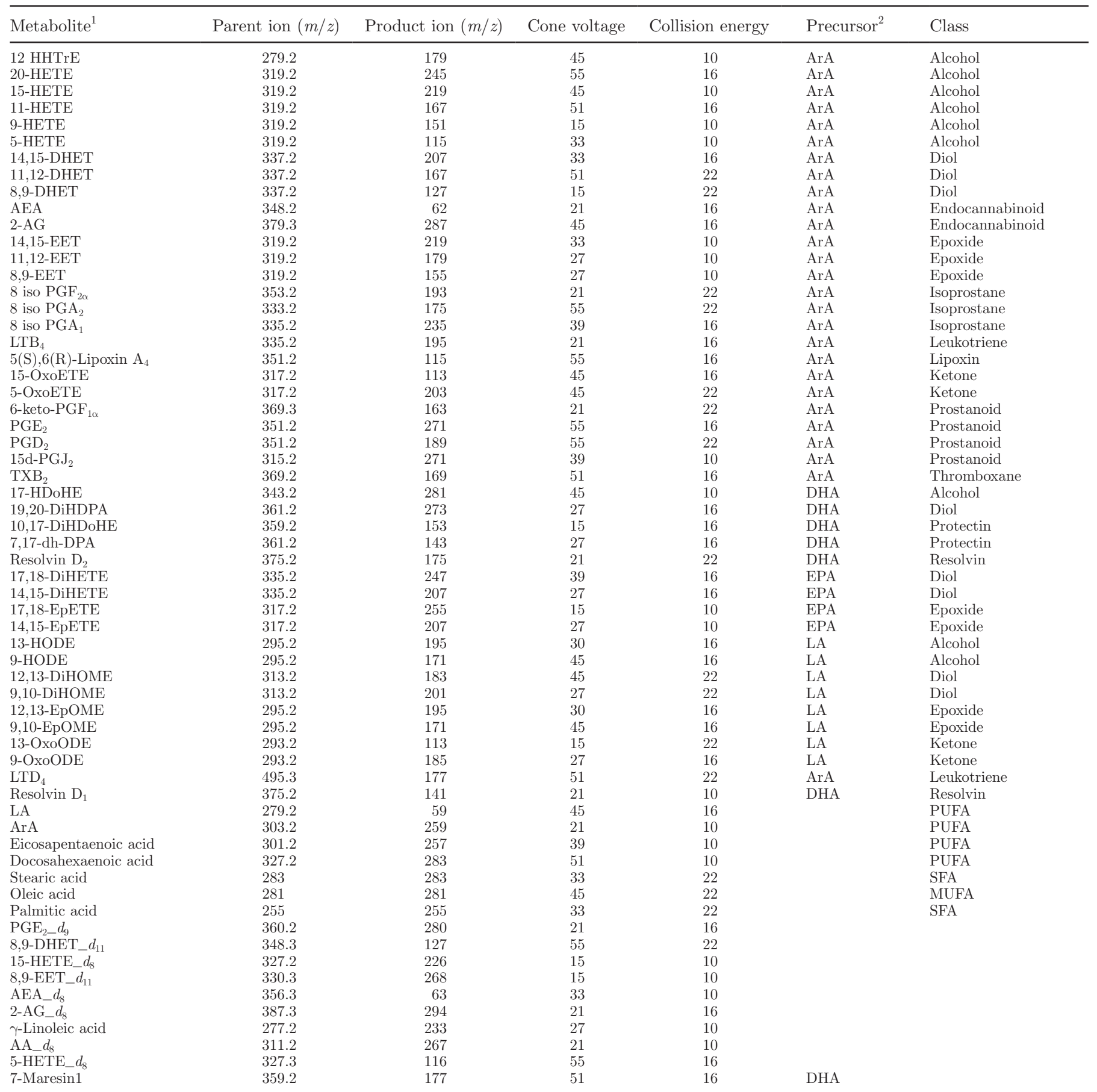

${ }^{1} \mathrm{HHTrE}=$ hydroxyheptadecatrienoic acid; HETE = hydroxyeicosatetraenoic acid; DHET = dihydroxyeicosatrienoic acid; AEA = arachidonoyl ethanolamide; $\mathrm{AG}=$ arachidonoyl glycerol; EET $=$ epoxyeicosatrienoic acid; $\mathrm{PG}=$ prostaglandin; $\mathrm{LTB}_{4}=$ leukotriene $\mathrm{B}_{4}$; oxoETE $=$ oxoeicosatetraenoic acid; $15 \mathrm{~d}-\mathrm{PG} \mathrm{J}_{2}=$ 15-deoxyprostaglandin $\mathrm{J}_{2}$; TXB2 = thromboxane B2; HDoHE = hydroxydocosahexaenoic acid; DiHDPA = dihydroxydocosapentaenoic acid; DiHDoHE = dihydroxydocosahexaenoic acid; 7,17-dh-DPA = 7,17-dihydroxydocosapentaenoic acid; DiHETE $=$ dihydroxyeicosatrienoic acid; EpETE = epoxyeicosatetraenoic acid; $\mathrm{HODE}=$ hydroxyoctadecadienoic acid; DiHOME $=$ dihydroxyoctadecenoic acid; EpOME $=$ epoxyoctadecenoic acid; oxoODE $=$ oxooctadecadienoic acid; LTD4 $=$ leukotriene D4; $\mathrm{PGE}_{2} \_d_{9}=$ prostaglandin E2-d9; 8,9-DHET_ $d_{11}=$ dihydroxyeicosatrienoic-d11 acid; 15 -HETE_d $d_{8}=$ hydroxyeicosatetraenoic-d8 acid; 8,9-EET_ $d_{11}$ $=$ epoxyeicosatrienoic-d1 1 acid; AEA $\_d_{8}=$ arachidonoyl ethanolamide-d8; 2 -AG_ $d_{8}=2$-arachidonoyl glycerol-d8; AA_d $d_{8}=$ arachidonic acid-d8; 5 -HETE_ $d_{8}=$ hydroxyeicosatetraenoic-d8 acid.

${ }^{2} \mathrm{ArA}=$ arachidonic acid; DHA = docosahexaenoic acid; EPA = eicosapentaenoic acid; LA = linoleic acid. 